\title{
Adrenal venous sampling: cosyntropin stimulation or not?
}

\author{
Jaap Deinum ${ }^{1,3}$, Hans Groenewoud ${ }^{2}$, Gert Jan van der Wilt ${ }^{2}$, Livia Lenzini ${ }^{4}$ and \\ Gian Paolo Rossi ${ }^{4}$
}

${ }^{1}$ Department of Internal Medicine, ${ }^{2}$ Department for Health Evidence, Radboud University Medical Center, Nijmegen, The Netherlands, ${ }^{3}$ Department of Medicine III, Institute of Clinical Chemistry and Laboratory Medicine, University Hospital Carl Gustav Carus, Technische Universität Dresden, Dresden, Germany, and ${ }^{4}$ Department of Medicine DIMED, Padova, Italy
Correspondence should be addressed to J Deinum Email Jaap.Deinum@radboudumc. nl or to G P Rossi Email: gianpaolo.rossi@unipd.it

\section{Abstract}

Notwithstanding the high prevalence of primary aldosteronism (PA), probably the most common form of secondary hypertension, the diagnosis of PA is often neglected or delayed, thus precluding target treatment, which is curative in many cases. For selection of the most appropriate treatment, a fundamental step is the distinction between a lateralized form, mainly aldosterone-producing adenoma (APA), and bilateral adrenocortical hyperplasia (BAH), also known as idiopathic hyperaldosteronism (IHA). To this aim all current guidelines recommend adrenal vein sampling (AVS), a technically challenging procedure that often fails, particularly in non-experienced hands. Cosyntropin (synthetic ACTH) is administered in the attempt to maximize adrenal cortisol secretion and avoid pulsatile adrenocortical hormone secretion in about $40 \%$ of the referral centres around the world. However, the Endocrine Society guidelines do not advise about the use or not of cosyntropin as stimulus during AVS, as there are arguments in favour and against its use. These arguments are presented in this debate article reflecting the views of groups that currently use and do not use cosyntropin.

\section{Introduction}

Patients referred to specialized centres for high blood pressure, regardless of the fact that their hypertension was drug resistant or not $(1,2)$, as well as findings obtained in general practice (3), have provided compelling evidence that primary aldosteronism (PA) is a highly prevalent form of secondary hypertension, probably the most common such forms. Notwithstanding this and the fact that PA carries an excess cardiovascular and renal damage (4), and thereby an increased risk of cardiovascular $(\mathrm{CV})(5,6)$ and renal events $(7,8)$, the diagnosis of PA is often neglected (9), or delayed, thus precluding specific treatments, which lead to cure in many cases. Target treatment of PA, and particularly adrenalectomy if a lateralized form is identified, has been shown to be highly effective in providing long-term biochemical cure, regression of left ventricular hypertrophy (10), and also lowering of the incidence of atrial fibrillation (7), the most common CV complication of PA $(5,6,11)$.

While with few exceptions, CT is advocated to rule out an aldosterone-producing adrenocortical carcinoma and to identify adrenal vein anatomy in preparation for adrenal vein sampling (AVS). All current guidelines recommend AVS $(12,13)$ for the subtyping of PA, that is for distinguishing between a lateralized form, mainly aldosterone-producing adenoma (APA), and bilateral adrenocortical hyperplasia (BAH), also known as idiopathic hyperaldosteronism.

AVS involves blood collection through catheterization of each adrenal vein and a peripheral vein, usually the iliac or the infrarenal inferior vena cava (IVC). To assess 
selectivity of the cannulation, cortisol is then measured in these samples to calculate the selectivity index (SI) (14), consisting of the ratio between plasma cortisol concentrations (PCC) in the adrenal vein and the IVC or the iliac vein. Bilateral selectivity, a prerequisite to define AVS success, and therefore for using the test for diagnostic purposes, is held to be accomplished if the SI value exceeds a given cut-off on each side.

The ultimate goal of AVS is, however, not just to achieve bilateral selectivity, but rather to demonstrate lateralisation of aldosterone excess, which is done by measuring aldosterone in these samples and correcting its values for the degree of AVS selectivity, i.e. the proximity of the catheter's tip to the site of production of the adrenocortical hormones - the adrenal cortex. This is done by calculating the lateralisation index (LI), i.e. by dividing the plasma aldosterone concentration (PAC) by the SI. The LI provides a diagnosis of lateralized PA when this ratio exceeds a certain cut-off, thus permitting to refer the patient for unilateral adrenalectomy. Unfortunately, available data indicate that AVS success is not a consistent achievement even at referral centres (15).

Some centres also calculate a so-called suppression index, consisting of the ratio of aldosterone-cortisol on the non-dominant adrenal divided by the same ratio in the inferior vena cava or a peripheral vein. A value lower than one would indicate suppression of aldosterone production, and thus supports adrenalectomy of the contralateral 'dominant' adrenal gland, but the evidence supporting the diagnostic accuracy of this approach remains scant.

Thus, even though an Expert Consensus paper provided some clear-cut recommendations (16), areas of uncertainties on how to best perform and interpret AVS persist. Likely this explains why very different ways of performing and interpreting this key test continue to exist, as shown in a multicentre international survey (15), which recently led to label AVS has as a 'cottage industry' product (17). One such uncertainties relate to establishing selectivity of catheterization with use of cortisol, which stands on the assumption that this hormone is secreted symmetrically, i.e. equally, by both adrenal cortexes in PA patients.

Some problems, however, are built in this assumption: first, cortisol is a stress hormone that, moreover, is secreted in a pulsatile fashion with cycling period of $10-30 \mathrm{~min}$, meaning that if stress occurs, as commonly seen during AVS, and/or if the procedure is not running smoothly, its concentration may be low at a time and much higher at another time, as unambiguously demonstrated in a study that assessed the effect of stress associated with AVS and reported a fall of cortisol from time $-15 \mathrm{~min}$ to time 0 (18). This can deeply affect the SI, and also the LI, if the adrenal veins and the peripheral vein are not sampled simultaneously. In fact, these pulsatile variations may blunt the SI values causing a procedure to be rejected because judged to be unsuccessful, and/or lead to miss lateralization when present, or even worse, to lateralize PA to the wrong side.

To overcome these problems some centres took the shortcut of administering cosyntropin (synthetic ACTH) during the procedure, either by intravenous bolus of $250 \mu \mathrm{g}$ or continuous infusion $(50 \mu \mathrm{g} / \mathrm{h})$ to maximize cortisol secretion, thus increasing the step-up of levels between the adrenal veins and eliminating the untoward effect of pulsatile adrenocortical hormone secretion.

But is it all gold that glitters? The Endocrine Society guidelines do not advise for or against the use of ACTH (13). Consequently recent surveys of AVS practices around the world show that about $40 \%$ of centres use ACTH infusion during AVS $(15,19)$. Therefore, a debate in this journal is appropriate and timely as arguments exist both for and against use of cosyntropin. Our divergent opinions, which we will present herein, may help the reader to decide whether or not to use this stimulation during AVS in their practice.

\section{The case for using cosyntropin during AVS}

Humans are inclined to remember and emphasise their successes and forget their failures. Clinicians are no exception and may base their belief about optimal patient care on successfully managed cases they encountered in practice. Regarding the question of whether to perform AVS with or without cosyntropin, clinical practice may be shaped by the following scenario. Patients undergo AVS without cosyntropin infusion first and then the procedure is repeated with cosyntropin. In a subset (but not all), cases both procedures are successful, as evidenced by obtaining an SI (adrenal vein cortisol-to-peripheral vein ratio) above the cut-off level, as explained in the introduction. Some of these cases may have discordant results between AVS without and with AVS regarding the unilaterality of aldosterone hypersecretion. Then, the clinician decides to base the decision to perform adrenalectomy in these discrepant cases on AVS without cosyntropin and finds a favourable clinical outcome. This outcome may seduce the clinician to conclude that indeed it is essential to perform AVS without cosyntropin infusion. Along the 
way the following patients are however lost or ignored: those in whom AVS failed altogether, those in whom only AVS with cosyntropin infusion was successful and those in whom AVS with cosyntropin infusion showed unilateral aldosterone hypersecretion but in whom AVS without cosyntropin did not. Probably most of these patients would be managed by MRA, with resulting loss of quality of life (20). A much better way of finding out whether cosyntropin infusion during AVS is necessary or had better be avoided is an outcome-based diagnostic study in which patients are randomised to either AVS without cosyntropin infusion or AVS with cosyntropin infusion. Outcome of adrenalectomy in terms of biochemical cure or blood pressure and medication use should then determine which strategy is best. Alas, such studies have not been done and neither our opponents nor we can base our argument on them.

There are however two arguments to prefer cosyntropin during AVS, which will be discussed hereafter.

\section{Unselective sampling more frequent in AVS without cosyntropin}

Notwithstanding the need for a prospective outcomebased diagnostic trial the most straightforward approach to estimate the effect of cosyntropin seems to be a comparison of adrenal and peripheral vein aldosterone and cortisol levels before and after cosyntropin, either by bolus or by continuous infusion. Table 1 summarises the findings from a few of such studies $(21,22,23)$, from which it can be concluded that the success rate of bilateral adrenal vein cannulation as evidenced by a sufficient step-up of cortisol increased by $20-30 \%$ by using cosyntropin. Surely this is not explained by a better dexterity of the interventionist performing AVS. After all, in these studies it can be safely assumed that the same interventionist positioned the catheters before and after cosyntropin infusion. Table 1 also shows that some groups use different criteria for selectivity (and lateralization) depending on whether cosyntropin was used or not. It should be realized that this may have influenced the findings, but evidence for that is lacking. Be that as it may, it is much more likely that basing a conclusion of unselective cannulation of an adrenal vein on cortisol level without cosyntropin infusion is sometimes wrong. Support for that is found in a paper in which selectivity was based on cortisol or metanephrine levels in adrenal veins. Metanephrine is a highly selective marker for blood of adrenal origin (24). In unstimulated samples, cannulation was unsuccessful in $44 \%$ of cases according to the adrenal vein cortisol-to-peripheral vein cortisol ratio. However, $24 \%$ of these samplings, that is more than half of them and a number remarkably similar to the values in Table 1, were selective according to metanephrine level. In cosyntropin-stimulated samples, cortisol levels led to the same conclusion as metanephrine levels in almost all patients. This means that it is unlikely that the inferior success rates of AVS without cosyntropin can be improved by more experienced radiologists if we stick to adrenal vein cortisol level as the criterion for selectivity. This also implies that if a sampling without cosyntropin is unsuccessful according to selectivity criteria, it is impossible to say whether this is due to inexperience of the radiologist or due to this $25 \%$ of procedures that escape detection of selectivity because for some reason cortisol levels fail to indicate selective adrenal vein cannulation. In particular in centres where the radiologist is still inexperienced, cosyntropin during AVS is therefore essential.

\section{Balancing higher success rates and less perfect subtyping after cosyntropin}

Table 1 also shows that the conclusion as to the subtype was concordant in only $70-90 \%$ of procedures that were successful both without and with cosyntropin. Although formal proof by a randomised trial for better subtyping by omitting cosyntropin is lacking, we might accept that applying cosyntropin leads to a wrong conclusion in a subset of cases. In the Spartacus trial, which applied cosyntropin infusion, adrenalectomy failed to provide biochemical improvement in about $10 \%$ of patients (25). This is similar to what was found in the PASO study (about $8 \%$ ) but that study also showed that AVS without cosyntropin may be fallible: adrenalectomies failed to cure PA in about $5 \%$ of patients in whom AVS without cosyntropin suggested an APA (26). Therefore, choosing to do AVS with or without cosyntropin depends on the balance between a considerably lower number of interpretable AVSs if no cosyntropin is used and a slightly larger number of failed adrenalectomies when cosyntropin infusion is applied. Put in other words, AVS without cosyntropin has a problem with the SI described in the introduction and AVS with cosyntropin has a problem with the LI.

But how can we address this balance? We can rephrase this question to: 'To what extent does the gain in benefit from a larger number of successful procedures compensate for a loss in benefit because the probability of an accurate diagnosis is lower?' We propose to do this 


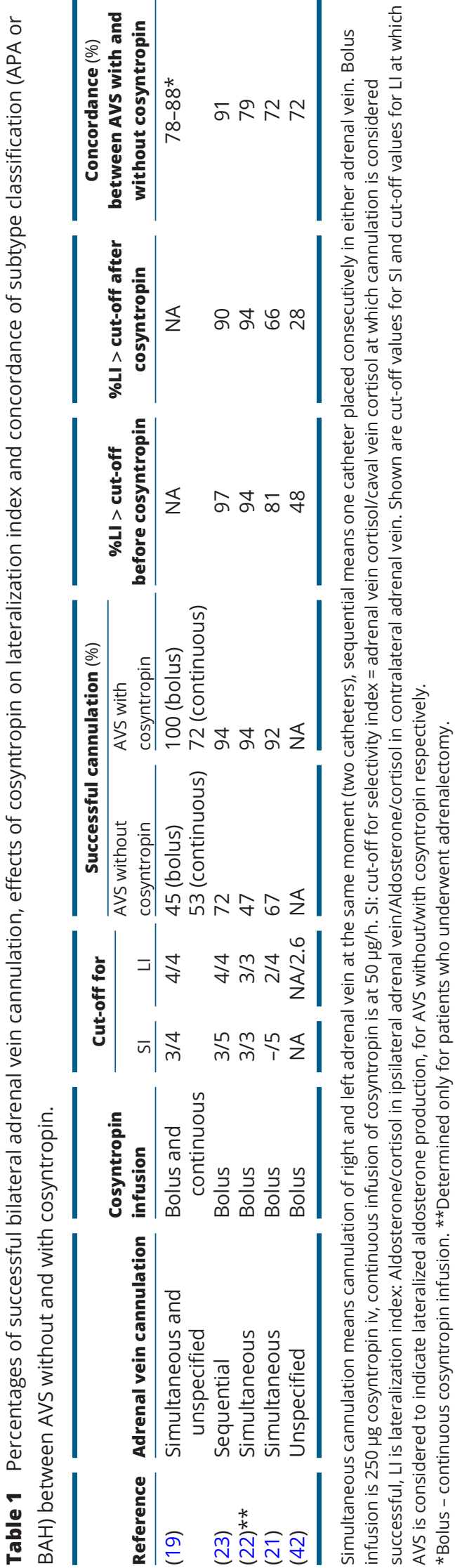

by a decision model. Using decision analysis may not provide a definitive answer to the question of whether to use cosyntropin infusion or not during AVS, but it may guide our thoughts and has the added advantage that it does not ignore the fate of the patients who do not undergo an adrenalectomy or in whom AVS fails. In a decision analysis, we consider the total value of performing AVS with or without cosyntropin as a sum for each procedure of the utilities, which can be considered as measures of benefit, for each of the possible outcomes, considering the probability of the outcome. Put simply, 'Is the value of using cosyntropin larger or as large as the value of performing AVS without cosyntropin infusion?' Unfortunately, literature provides not all data that are required to calculate this value, but a reasonable estimation of the size of these parameters is possible.

A key issue for building a model is what will happen with patients who have a failed AVS. Surely an adrenal CT scan will be available in these patients and although the Endocrine Society guideline (13) does not consider CT-scanning to perform as well as AVS for subtyping, the clinical results of relying on CT may not be very different from AVS (25). Nevertheless, assuming CT is not as good as AVS (why do AVS if this were not the case?), it is possible to estimate the loss of benefit to patients in which management has to be decided based on CT because the AVS procedure failed.

\section{Building the model}

In the model for diagnostic flow in PA (Fig. 1), we assigned probabilities to branching points and utilities to different outcomes. We based these probabilities and utilities on data and estimates from the literature (Table 2). For some of the values and probabilities, no literature base exists, and we estimated these. A most important assumption, based on Table 1, is that using cosyntropin leads to at least $20 \%$ increase in success rate of the AVS. Another important assumption is that having $\mathrm{BAH}$, or undergoing adrenalectomy wrongfully when having $\mathrm{BAH}$, or not undergoing adrenalectomy when having APA have a similar utility determined by being persistently hypertensive due to hyperaldosteronism. We considered the utility of having an adrenal successfully removed because of APA as a 1:1 balance of the utility of being normotensive (0.88) (27) and being normotensive with medication (0.86, estimated) for the Dutch population (27). Likewise, we considered the utility of having $\mathrm{BAH}$, of having an adrenal wrongfully removed and of not undergoing adrenalectomy in case of APA as a similar balance of the 


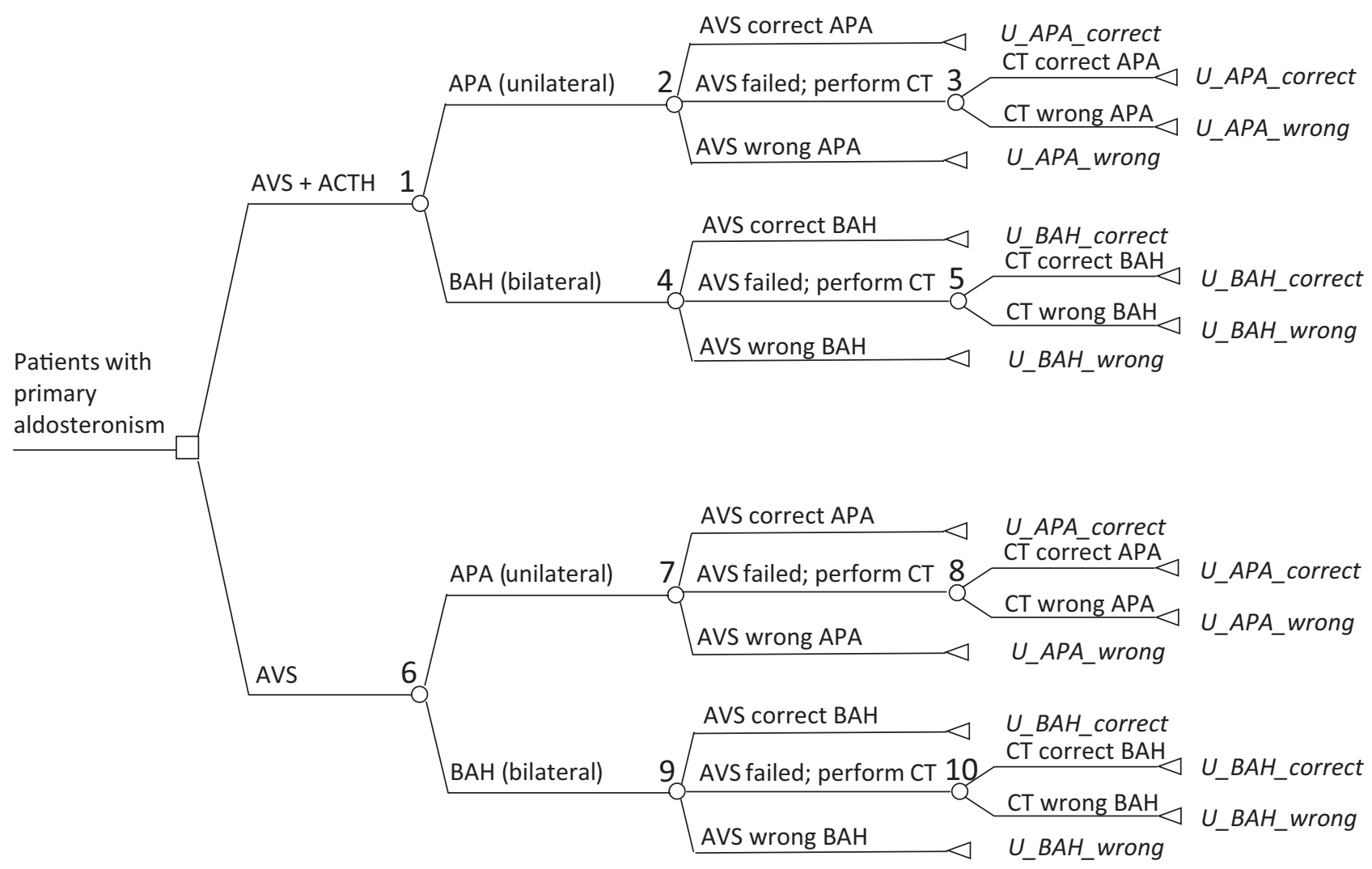

\section{Figure 1}

Decision tree for the diagnosis of aldosterone-producing adenoma (APA) or bilateral adrenal hyperplasia (BAH) by adrenal vein sampling. For probabilities at branching points and meaning of abbreviations see Table 2 .

utility of being normotensive with medication $(0.86)$ and being hypertensive with medication (0.83). In all three situations, PA persists, which calls for specific treatment with mineralocorticoid receptor antagonists. Even though this treatment probably is as effective with regard to blood pressure and potassium as adrenalectomy, it leads to a somewhat lower quality of life (20). This warrants a slightly lower utility. We further assumed that if bilaterally selective cannulation of the adrenal veins failed a clinician would manage the patient according to the result of the adrenal CT scan. This means that if a unilateral adrenal enlargement is observed with the characteristics of an adenoma with a normal contralateral adrenal gland, the patient would be operated. Although CT scanning performed as well as AVS in the Spartacus study (25), we assumed it was inferior and used data from the systematic review by Kempers et al. (28).

The model was developed and analysed using Microsoft Office Excel 2016 and is available upon request. We expressed benefit (value) of using and not using cosyntropin during AVS as the sum of the probabilities multiplied by the utilities of the outcomes in both branches (using cosyntropin or not) of Fig. 1. In order to validate the model, we performed a probability sensitivity analysis using the TreeAge package (Pro version $2015 \mathrm{R}$ 1.0. Williamstown, MA, USA). The program uses the values of the table and estimates of their range to perform a MonteCarlo simulation. We chose to perform 1000 simulations and calculated for each simulation the utility for basal AVS and AVS with cosyntropin.

According to this model, the value of management of patients with PA is slightly higher when it is based on AVS that uses cosyntropin than when basal AVS, without cosyntropin infusion, determines management. The difference however is small (a value of 0.8574 vs 0.8571 for AVS with vs without cosyntropin respectively). A probability sensitivity analysis shows a mean difference of the utility of 0.0003 in favour of performing AVS with cosyntropin; $57.3 \%$ of the simulations showed a higher utility for basing management on AVS with cosyntropin.

This model has the advantage that it encompasses all patients with PA, not just patients that undergo 
Table 2 Parameters used for calculating value of performing AVS with or without cosyntropin infusion.

\begin{tabular}{|c|c|c|c|c|}
\hline Code & $\begin{array}{l}\text { Branching } \\
\text { point in Fig. } 1\end{array}$ & Meaning & Value & Justification \\
\hline P_APA & 1 and 6 & $\begin{array}{l}\text { Probability of having an aldosterone-producing } \\
\text { adenoma }\end{array}$ & 0.5 & Estimation from (28) \\
\hline P_AVS_ACTH_ & 2 & & & $\begin{array}{l}\text { From (26), } 5 / 46 \text { patients had biochemical failure } \\
\text { after adrenalectomy, percentage of unsuccessful } \\
\text { AVS procedure with cosyntropin is } \sim 4 \%\end{array}$ \\
\hline Correct_APA & & $\begin{array}{l}\text { Probability of correctly identifying APA by AVS } \\
\text { using cosyntropin }\end{array}$ & 0.86 & \\
\hline Failed_APA & & $\begin{array}{l}\text { Probability of missing an APA because the AVS } \\
\text { using cosyntropin was unsuccessful (perform } \\
\text { CT scan) }\end{array}$ & 0.04 & \\
\hline Wrong_APA & & $\begin{array}{l}\text { Probability of incorrectly identifying an APA by } \\
\text { AVS using cosyntropin (when BAH is present) }\end{array}$ & 0.1 & \\
\hline $\mathrm{P}_{-} \mathrm{CT}_{-}$ & 3 and 8 & & & From (30) \\
\hline Correct_APA & & $\begin{array}{l}\text { Probability of correctly identifying an APA by } \\
\text { adrenal CT scan }\end{array}$ & 0.6 & \\
\hline Wrong_APA & & $\begin{array}{l}\text { Probability of incorrectly identifying APA (when } \\
\text { BAH was present) }\end{array}$ & 0.4 & \\
\hline P_AVS_ACTH_ & 4 & & & $\begin{array}{l}\text { Assumption that these values are similar for APA } \\
\text { and for BAH (see above, branching point } 2 \text { ) }\end{array}$ \\
\hline Correct_BAH & & $\begin{array}{l}\text { Probability of correctly identifying BAH by AVS } \\
\text { using cosyntropin }\end{array}$ & 0.86 & \\
\hline Failed_BAH & & $\begin{array}{l}\text { Probability of missing a BAH because the AVS } \\
\text { using cosyntropin was unsuccessful }\end{array}$ & 0.04 & \\
\hline Wrong_BAH & & $\begin{array}{l}\text { Probability of incorrectly identifying BAH by AVS } \\
\text { using cosyntropin (when APA was present) }\end{array}$ & 0.1 & \\
\hline $\mathrm{P}_{-} \mathrm{CT}_{-}$ & 5 and 10 & & & $\begin{array}{l}\text { Assumed that these values are similar for APA and } \\
\text { BAH (branching points } 3 \text { and } 8 \text { ) }\end{array}$ \\
\hline Correct_BAH & & $\begin{array}{l}\text { Probability of correctly identifying BAH by } \\
\text { CT-scanning }\end{array}$ & 0.6 & \\
\hline Wrong_BAH & & $\begin{array}{l}\text { Probability of incorrectly identifying APA (when } \\
\text { BAH was present) }\end{array}$ & 0.4 & \\
\hline$P_{-}$AVS_ & 7 & & & $\begin{array}{l}\text { From (27), appendix: } 5 \% \text { of adrenalectomies result } \\
\text { in biochemical failure. Probability of } \\
\text { unsuccessful procedure is } \sim 25 \% \text { (about } 20 \% \\
\text { more than when using cosyntropin, see Table 1) }\end{array}$ \\
\hline Correct_APA & & Probability of correctly identifying APA by AVS & 0.7 & \\
\hline Failed_APA & & $\begin{array}{l}\text { Probability of missing an APA because the AVS } \\
\text { was unsuccessful }\end{array}$ & 0.25 & \\
\hline Wrong_APA & & $\begin{array}{l}\text { Probability of incorrectly identifying an APA by } \\
\text { AVS (when BAH is present) }\end{array}$ & 0.05 & \\
\hline P_AVS_ & 9 & & & $\begin{array}{l}\text { Assumption that these values are similar for APA } \\
\text { and for BAH (see above branching point 7) }\end{array}$ \\
\hline Correct_BAH & & Probability of correctly identifying BAH by AVS & 0.7 & \\
\hline Failed_BAH & & $\begin{array}{l}\text { Probability of missing a BAH because the AVS } \\
\text { was unsuccessful }\end{array}$ & 0.25 & \\
\hline Wrong_BAH & & $\begin{array}{l}\text { Probability of incorrectly identifying BAH by AVS } \\
\text { (when APA was present) }\end{array}$ & 0.05 & \\
\hline$U_{-} A_{P A}$ & - & & & See text \\
\hline Correct & & $\begin{array}{l}\text { Utility of correctly identifying an APA (and } \\
\text { undergoing successful ADX) }\end{array}$ & 0.87 & \\
\hline Wrong & & $\begin{array}{l}\text { Utility of incorrectly identifying APA (and } \\
\text { undergoing unsuccessful ADX) }\end{array}$ & 0.85 & \\
\hline U_BAH_ & - & & & \\
\hline Correct & & Utility of correctly identifying a BAH & 0.85 & \\
\hline wrong & & $\begin{array}{l}\text { Utility of incorrectly identifying a BAH (when } \\
\text { APA is present and ADX would be warranted } \\
\text { but is not performed) }\end{array}$ & 0.85 & \\
\hline
\end{tabular}

Codes refer to codes used in the Excel model (available on request). 'ACTH' in the codes stands for adrenocorticoptropic hormone = cosyntropin. 
an adrenalectomy. A weakness of the model is that a few variables in Table 2 are estimates, in particular the probabilities for the BAH arms (branching points 4 and 9 of Fig. 1). It is conceivable that AVS without cosyntropin misses APAs more often than AVS with cosyntropin: suppose the conclusion of unstimulated AVS is that a patient has BAH, where in reality a small APA is present. This patient will not be operated, and we will most likely never know that an adenoma was present because only adrenalectomy and subsequent (biochemical) cure of PA would have proven the existence of an APA. If this situation occurs less when cosyntropin infusion is used, the worth of using cosyntropin is further increased. However, this cannot be proven because we do not have the check of adrenalectomy. This realisation makes it even more urgent to perform a randomised trial as described above in which the outcomes of management based on AVS with cosyntropin are compared with outcomes of management based on AVS without cosyntropin.

It is clear now that the major problem of performing AVS without cosyntropin infusion is in the considerably lower success percentage. As discussed above, it is unlikely to improve by more experienced radiologists. Rather, in a substantial number of procedures, it seems that the use of cortisol to judge selective sampling is the problem. Note that we have not discussed why this might occur. Neither have we discussed why cosyntropin-stimulated AVS may lead more often to erroneous conclusions regarding unilaterality of aldosterone production, but it is not unlikely that again the use of cortisol in determining LIs is the culprit. Discussion of the possible mechanisms of these diagnostic failures is however beyond the scope of our argument. What we can only say now is that for clinical practice a more pertinent question than whether or not to apply cosyntropin stimulation is whether we should continue to rely on cortisol as a comparator and calibrator in AVS.

In conclusion AVS without cosyntropin infusion is much less successful in meeting the criteria for selective sampling than AVS with cosyntropin. This is a consistent finding that is probably caused by the use of cortisol to determine selectivity. It is unlikely to improve with more experience in performing AVS. Even if omitting cosyntropin may result in better prediction of successful adrenalectomies, this does not compensate for the problem of unsuccessful procedures when doing without cosyntropin. Research efforts to improve subtyping of PA should be directed at randomised outcome-based diagnostic trials or at better ways to assess selectivity and lateralisation. In the meantime, the use of cosyntropin during AVS is to be preferred.

\section{The case against using cosyntropin during AVS}

As the famous statistician Edwards W. Deming, the creator of Deming's regression, used to state, 'without data you are just another person with an opinion'. Therefore, to address the issue of whether to use, or not to use, cosyntropin stimulation during AVS, we have elected to stick with the data, which means to examine only the studies that have performed a head-to-head withinpatient comparison of the SI and the LI between baseline (unstimulated) and post-cosyntropin values. This was because the published studies that reported only postcosyntropin data are by no means usable to understand what cosyntropin does to these indexes, and therefore, useless to support or confute the use of cosyntropin, i.e. the topic of the present discussion.

To start the discussion properly, it should be acknowledged that cosyntropin stimulation can be performed in different ways. The very low dose of cosyntropin $(250 \mathrm{pg})$, which was reported in one of the first papers proposing the use of cosyntropin during AVS (29), resulted to be totally ineffective in raising PCC and PAC, both in the IVC and in the peripheral veins blood when tested with an appropriate within-patient controlled study design (30). Nonetheless, this exquisitely 'homeopathic' dose was used in following studies that were quoted to support the usefulness of cosyntropin.

Two different protocols using $10^{6}$ higher doses have been proposed: (a) the Mayo Clinic protocol, with continuous cosyntropin infusion $(50 \mu \mathrm{g} / \mathrm{h})$ starting $30 \mathrm{~min}$ before sampling and continuing throughout the procedure; (b) the $250 \mu \mathrm{g}$ bolus, followed or not by continuous infusion.

When these two protocols were tested in a prospective study, where patients were studied both unstimulated (31), and after cosyntropin stimulation (30), the results were clear-cut: (1) there were no significant differences in cortisol and aldosterone response between protocols; (2) compared to unstimulated values, cosyntropin did increase the PCC step-up between the adrenal vein and the IVC blood and thus the SI values. Thereby, it rendered much easier the ascertainment of success in achieving selective catheterization. This conclusion was endorsed by the Experts Consensus document in 2014 (16) and reinforced by the finding of a larger study that provided compelling and conclusive evidence that the SI increases with cosyntropin (32).

It is, however, to be underlined that bilaterally selective catheterization could not be achieved even with 
use of cosyntropin in a proportion of the patients (32), likely because of the presence of anatomic variants of adrenal vein drainage, which involve between 10 and 15\% of the cases $(33,34)$. To put it simple, cosyntropin raises the PCC step-up between the adrenal vein and the IVC, but does not move catheters to the right place, neither can it correct for anatomic variations!

Accordingly, there is no arguments with our opponents that cosyntropin can be useful at centres with limited expertise in performing AVS, i.e. that are 'beginners' in the field, and/or have a low success rate in achieving bilateral selectivity.

\section{Is this cortisol step-up increase really a worth accomplishment?}

Probably not! This is because this facilitation comes with a price to pay in terms of lateralization. In fact, when considering only the AVS studies that were bilaterally selective under both unstimulated and cosyntropinstimulated conditions, cosyntropin induced a significantly decrease of the LI (Table 1). This decrease results into a proportion of cases judged to be non-lateralized, if a high cut-off value is used to define lateralization, which means that many patients would be denied curative adrenalectomy, even though they lateralized under unstimulated conditions and possibly had a lateralized PA that could have been cured by adrenalectomy.

If a lower cut-off of the LI is used to diagnose lateralization, this can result into opposite results under unstimulated vs cosyntropin-stimulated conditions, which could lead to the decision to remove different adrenals based on which result one trusts on, or, more commonly, to take no clinical decision and assign the patient to long-term medical therapy. Under the latter eventuality, the patients seeking for a surgical cure were submitted to an invasive, expensive test, as AVS, without getting a diagnosis in return. Moreover, they are left exposed to a higher risk of cardiovascular events, particularly atrial fibrillation, as compelling evidences $(5,6)$, also from a recent long-term prospective study (7) has shown.

\section{Why cosyntropin lowers the LI thus causing these worrying results?}

The answer to this question was recently provided by a number of studies that our group undertook. As mentioned earlier, the LI is the ratio of PAC on the dominant and the non-dominant side corrected for the degree of selectivity, that is the SI, of each side. However, use of a different index, the relative aldosterone secretion index (RASI), is necessary to truly understand what happens with cosyntropin. The RASI, originally introduced by Espiner et al. as 'central/peripheral ratio' (35), and then proposed by Rossitto et al. to dissect the contribution of the culprit and non-culprit adrenal to the LI value (36), is the ratio of PAC in each adrenal vein corrected for the degree of selectivity, that is divided by the ratios of PCC in each adrenal vein and the IVC or a peripheral vein. It can be easily verified arithmetically that the LI is derived from the ratio of the RASI of each side, given that:

$$
\text { RASI }=(\text { PACside } / \text { PACivc }) /(\text { PCCside } / \text { PCCivc })
$$

and

$$
\mathrm{LI}=(\text { PACside } / \text { PCCside }) /(\text { PACnon dom/PCCnon dom })
$$

Table 3 Melanocortin 2 receptor gene expression in aldosterone-producing adenoma and normal adrenal gland in the literature.

\begin{tabular}{lcc}
\hline Reference number & & MC2R expression in APA $(\mathrm{n})$ \\
\cline { 1 - 1 }$(43)$ & $175 \pm 29(9)$ \\
$(44)$ & $\mathrm{NA}(11)$ \\
$(45)$ & $154 \pm 26(4)$ \\
$(46)$ & $\mathrm{NA}(10)$ \\
& $5.24 \pm 0.71(28)$ \\
$(47)$ & $274(14)$ \\
$(48)^{\star}$ & $3683(2)$ \\
$(49)$ & $\mathrm{NA}(7)$ \\
$(50)$ & $\mathrm{NA}(7)$ \\
\hline
\end{tabular}

\begin{tabular}{c}
\hline MC2R expression in NAG $(\mathrm{n})$ \\
\hline $100 \pm 12(8)$ \\
$\mathrm{NA}(8)$ \\
$100 \pm 12(5)$ \\
$\mathrm{NA}(5)$ \\
$\mathrm{NA}(9)$ \\
$100(6)$ \\
$1591(62)$ \\
$\mathrm{NA}(7)$ \\
$\mathrm{NA}(7)$
\end{tabular}

\begin{tabular}{l} 
Fold change \\
\hline 1.75 \\
High \\
1.54 \\
4.24 \\
Normal range \\
2.74 \\
2.31 \\
3.71 \\
10.19
\end{tabular}

\begin{tabular}{l}
\hline Quantification method \\
\hline Northern blot \\
NA \\
Northern blot \\
Oligomicroarrays \\
Quantitative real-time PCR \\
Quantitative real-time PCR \\
Oligomicroarrays \\
Oligomicroarrays \\
Oligomicroarrays
\end{tabular}

The value of expression reported by the authors are in different units and therefore are not comparable among the studies.

*For this study, the data were extracted from the GEO Database (Dataset GSE28476).

APA, aldosterone-producing adenoma; NA, data not available; NAG, normal adrenal gland. 
Hence, since the RASI provides an estimate of the amount of aldosterone made and released by each adrenal, the within-patient comparison of the RASI value between the unstimulated and the cosyntropinstimulated condition allows to clarify what cosyntropin truly does to aldosterone secretion in the affected and the contralateral adrenal. By using this approach in a cohort of PA patients where the diagnosis was made conclusively by the 'four corner criteria' that are based on demonstration of cure post-adrenalectomy (37), we could demonstrate that cosyntropin significantly lowers the RASI on the affected side, while leaving it relatively unaffected in the contralateral side. This provides a straightforward explanation as to why, on average, the LI falls significantly.

\section{By which mechanisms the RASI falls in the affected side?}

The answer to this question came from investigation of the expression of the receptor for ACTH, the melanocortin type 2 receptor $(\mathrm{MC} 2 \mathrm{R})$, in $\mathrm{APA}$ and the normal adrenal cortex. Table 3 summarizes the studies that have measured

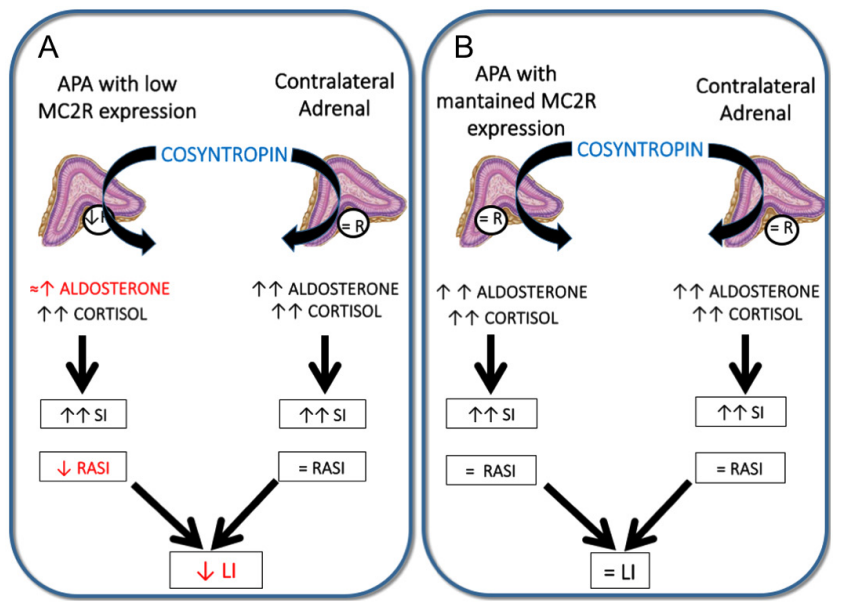

\section{Figure 2}

The cartoon summarizes the effects of cosyntropin on the adrenal gland with an APA with low (Panel A) or a maintained (Panel B) expression of the melanocortin type 2 receptor (MC2R) and on the contralateral normal adrenal gland. In APA with low melanocortin type 2 receptor expression, cosyntropin decreases the relative aldosterone secretion index (RASI), and thereby the lateralization index (LI), because it increases cortisol more than aldosterone via the MC2R. In APA where the $\mathrm{MC2R}$ expression is maintained cosyntropin raises the RASI similarly on both sides and therefore has no effect on the LI. the MC2R mRNA in APA. Most of these studies where performed in APA selected on the basis of cosyntropinstimulated AVS, as it can be readily appreciated; moreover, the techniques used for quantification of mRNA were largely semiquantitative and to be regarded as obsolete by modern standards. Finally, the studies were too small to provide any meaningful conclusions.

To solve these uncertainties, we undertook an unsupervised analysis of the whole transcriptome of APA in patients, who were not preselected based on post-cosyntropin AVS, and compared the mRNA level of APA and the normal adrenal cortex of patient adrenalectomized for renal cancer. This analysis allowed to discover that the cosyntropin receptor gene $M C 2 R$ is under-expressed in about two-thirds of the APA as compared to the normal adrenal cortex (32). Moreover, the $M C 2 R$ expression was directly related with that of $C Y P 11 B 2$, indicating that only the most florid cases of APA, notably a minority of all, overexpress the MC2R. From the functional standpoint, these results indicate that, while the contralateral adrenal responds to cosyntropin with a prominent cortisol secretion and a less prominent aldosterone secretion, the APA gland responds less in terms of cortisol and even much less so in terms of aldosterone (Fig. 2). These changes of MC2R receptors, and consequently of hormonal responses, have an unquestionable effect on the RASI of each side, and therefore, explain why the LI on average falls and/or inverts lateralization in a proportion of the cases.

In summary, available data showed that the use of cosyntropin stimulation can be justified only at centres that have a low experience/success rate in achieving bilateral selectivity and are unable to perform bilaterally simultaneous catheterization. We strongly support the view that the latter catherization technique should be the state-of the art method, as it was shown to avoid the untoward effect of pulsatile hormone secretion (38). In contrast, the use of cosyntropin stimulation is not justified at centres that are more proficient in performing AVS because of the confounding effect that cosyntropin exerts on lateralization.

The most urgent step to be undertaken at this stage is to train interventionists on how to optimal perform AVS to achieve bilateral success by using strategies as, for example, the intraprocedural rapid cortisol assay (39), whose usefulness is being tested in the ongoing I-PADUA (Intra-Procedural Cortisol Assay During Adrenal Vein Sampling Study) (40) and to make use of biomarkers of selectivity better than cortisol, as androstenedione (41), rather than to plan outcome-based randomized trials. 
These studies, besides being hardly feasible as it will take years to recruit the sizable number of patients that are necessary to demonstrate significant between-arm differences of outcomes that have a low incidence rate (7), will also be affected by significant across-patients variability, as those receiving cosyntropin will not be those that will not.

As a final remark one should consider a very simple fact that follows William of Occam's (Doctor Invincibilis motto): Frustra fit per plura quod potest fieri per pauciora: it is useless to make with more what can be done with less: AVS is by no means performed to the goal of achieving high values of the SI, but to demonstrate lateralization, which is key for referring for adrenalectomy our PA patients who seek and deserve surgical cure. As acknowledged by our opponents, this goal is not consistently provided by cosyntropin stimulation.

\section{Declaration of interest}

The authors declare that there is no conflict of interest that could be perceived as prejudicing the impartiality of this article.

\section{Funding}

G P Rossi and L Lenzini's study was supported by research grants by the International PhD Program in Arterial Hypertension and Vascular Biology of the University of Padova, and by FORICA (The Foundation for advanced Research In Hypertension and Cardiovascular diseases). For this paper J D received support from the Deutsche Forschungsgemeinschaft (DGE, German Research Foundation, Projektnummer 314061271-TRR 205; H G and G J v d W did not receive any specific grant from any funding agency in the public, commercial or not-for-profit sector.

\section{References}

1 Rossi GP, Bernini G, Caliumi C, Desideri G, Fabris B, Ferri C, Ganzaroli C, Giacchetti G, Letizia C, Maccario M et al. A prospective study of the prevalence of primary aldosteronism in 1,125 hypertensive patients. Journal of the American College of Cardiology 200648 2293-2300. (https://doi.org/10.1016/j.jacc.2006.07.059)

2 Douma S, Petidis K, Doumas M, Papaefthimiou P, Triantafyllou A, Kartali N, Papadopoulos N, Vogiatzis K \& Zamboulis C. Prevalence of primary hyperaldosteronism in resistant hypertension: a retrospective observational study. Lancet 2008371 1921-1926. (https://doi.org/10.1016/S0140-6736(08)60834-X)

3 Monticone S, Burrello J, Tizzani D, Bertello C, Viola A, Buffolo F, Gabetti L, Mengozzi G, Williams TA, Rabbia F et al. Prevalence and clinical manifestations of primary aldosteronism encountered in primary care practice. Journal of the American College of Cardiology 201769 1811-1820. (https://doi.org/10.1016/j.jacc.2017.01.052)

4 Rossi GPP, Sechi LA, Giacchetti G, Ronconi V, Strazzullo P \& Funder JW. Primary aldosteronism: cardiovascular, renal and metabolic implications. Trends in Endocrinology and Metabolism 2008 19 88-90. (https://doi.org/10.1016/j.tem.2008.01.006)

5 Wu VC, Wang SM, Chang CH, Hu YH, Lin LY, Lin YH, Chueh SCJ, Chen L \& Wu KD. Long term outcome of aldosteronism after target treatments. Scientific Reports 20166 32103. (https://doi.org/10.1038/ srep32103)
6 Hundemer GL, Curhan GC, Yozamp N, Wang M \& Vaidya A. Cardiometabolic outcomes and mortality in medically treated primary aldosteronism: a retrospective cohort study. Lancet: Diabetes and Endocrinology 20186 51-59. (https://doi.org/10.1016/S22138587(17)30367-4)

7 Rossi GP, Maiolino G, Flego A, Belfiore A, Bernini G, Fabris B, Ferri C, Giacchetti G, Letizia C, Maccario M et al. Adrenalectomy lowers incident atrial fibrillation in primary aldosteronism patients at long TermNovelty and significance. Hypertension 201871 585-591. (https://doi.org/10.1161/HYPERTENSIONAHA.117.10596)

8 Rossi GP, Bernini G, Desideri G, Fabris B, Ferri C, Giacchetti G, Letizia C, Maccario M, Mannelli M, Matterello MJ et al. Renal damage in primary aldosteronism: results of the PAPY study. Hypertension 200648 232-238. (https://doi.org/10.1161/01. HYP.0000230444.01215.6a)

9 Mulatero P, Monticone S, Burrello J, Veglio F, Williams TA \& Funder J. Guidelines for primary aldosteronism: uptake by primary care physicians in Europe. Journal of Hypertension 201634 2253-2257. (https://doi.org/10.1097/HJH.0000000000001088)

10 Rossi GP, Cesari M, Cuspidi C, Maiolino G, Cicala MV, Bisogni V, Mantero F \& Pessina AC. Long-term control of arterial hypertension and regression of left ventricular hypertrophy With treatment of primary aldosteronism. Hypertension 201362 62-69. (https://doi. org/10.1161/HYPERTENSIONAHA.113.01316)

11 Milliez P, Girerd X, Plouin PF, Blacher J, Safar ME \& Mourad JJ. Evidence for an increased rate of cardiovascular events in patients with primary aldosteronism. Journal of the American College of Cardiology 200545 1243-1248. (https://doi.org/10.1016/j. jacc.2005.01.015)

12 Nishikawa T, Omura M, Satoh F, Shibata H, Takahashi K, Tamura N, Tanabe A \& Task Force Committee on Primary Aldosteronism, The Japan Endocrine Society. Guidelines for the diagnosis and treatment of primary aldosteronism - the Japan Endocrine Society 2009. Endocrine Journal 201158 711-721. (https://doi.org/10.1507/endocrj. EJ11-0133)

13 Funder JW, Carey RM, Mantero F, Murad MH, Reincke M, Shibata H, Stowasser M \& Young WF. The management of primary aldosteronism: case detection, diagnosis, and treatment: an Endocrine Society clinical practice guideline. Journal of Clinical Endocrinology and Metabolism 2016101 1889-1916. (https://doi. org/10.1210/jc.2015-4061)

14 Rossi GP, Sacchetto A, Chiesura-Corona M, De Toni R, Gallina M, Feltrin GP \& Pessina AC. Identification of the etiology of primary aldosteronism with adrenal vein sampling in patients with equivocal computed tomography and magnetic resonance findings: results in 104 consecutive cases. Journal of Clinical Endocrinology and Metabolism 200186 1083-1090. (https://doi.org/10.1210/ jcem.86.3.7287)

15 Rossi GP, Barisa M, Allolio B, Auchus RJ, Amar L, Cohen D, Degenhart C, Deinum J, Fischer E, Gordon R et al. The Adrenal Vein Sampling International Study (AVIS) for identifying the major subtypes of primary aldosteronism. Journal of Clinical Endocrinology and Metabolism 201297 1606-1614. (https://doi.org/10.1210/ jc.2011-2830)

16 Rossi GP, Auchus RJ, Brown M, Lenders JWM, Naruse M, Plouin PF, Satoh F, Young WF \& Young Jr WF. An expert consensus statement on use of adrenal vein sampling for the subtyping of primary aldosteronism. Hypertension 201463 151-160. (https://doi. org/10.1161/HYPERTENSIONAHA.113.02097)

17 Funder JW. Primary aldosteronism: the next five years. Hormone and Metabolic Research 201749 977-983. (https://doi. org/10.1055/s-0043-119802)

18 Seccia TM, Miotto D, Battistel M, Motta R, Barisa M, Maniero C, Pessina AC \& Rossi GP. A stress reaction affects assessment of selectivity of adrenal venous sampling and of lateralization of aldosterone excess in primary aldosteronism. European Journal of 
Endocrinology 2012166 869-875. (https://doi.org/10.1530/EJE-110972)

19 Monticone S, Satoh F, Giacchetti G, Viola A, Morimoto R, Kudo M, Iwakura Y, Ono Y, Turchi F, Paci E et al. Effect of adrenocorticotropic hormone stimulation during adrenal vein sampling in primary aldosteronism. Hypertension 201259 840-846. (https://doi. org/10.1161/HYPERTENSIONAHA.111.189548)

20 Velema M, Dekkers T, Hermus A, Timmers H, Lenders J, Groenewoud H, Schultze Kool L, Langenhuijsen J, Prejbisz A, van der Wilt GJ et al. Quality of life in primary aldosteronism: a comparative effectiveness study of adrenalectomy and medical treatment. Journal of Clinical Endocrinology and Metabolism 2018103 16-24. (https://doi. org/10.1210/jc.2017-01442)

21 El Ghorayeb N, Mazzuco TL, Bourdeau I, Mailhot JP, Zhu PS, Thérasse E \& Lacroix A. Basal and post-ACTH aldosterone and its ratios are useful during adrenal vein sampling in primary aldosteronism. Journal of Clinical Endocrinology and Metabolism 2016 101 1826-1835. (https://doi.org/10.1210/jc.2015-3915)

22 Kline GA, So B, Dias VC, Harvey A \& Pasieka JL. Catheterization during adrenal vein sampling for primary aldosteronism: failure to use (1-24) ACTH may increase apparent failure rate. Journal of Clinical Hypertension 201315 480-484. (https://doi.org/10.1111/ jch.12096)

23 Wolley MJ, Ahmed AH, Gordon RD \& Stowasser M. Does ACTH improve the diagnostic performance of adrenal vein sampling for subtyping primary aldosteronism? Clinical Endocrinology 201685 703-709. (https://doi.org/10.1111/cen.13110)

24 Dekkers T, Deinum J, Schultzekool LJ, Blondin D, Vonend O, Hermus ARRM, Peitzsch M, Rump LC, Antoch G, Sweep FCGJ et al. Plasma metanephrine for assessing the selectivity of adrenal venous sampling. Hypertension 201362 1152-1157. (https://doi.org/10.1161/ HYPERTENSIONAHA.113.01601)

25 Dekkers T, Prejbisz A, Kool LJS, Groenewoud HJMM, Velema M, Spiering W, Kołodziejczyk-Kruk S, Arntz M, Kądziela J, Langenhuijsen JF et al. Adrenal vein sampling versus CT scan to determine treatment in primary aldosteronism: an outcome-based randomised diagnostic trial. Lancet: Diabetes and Endocrinology 20164 739-746. (https://doi.org/10.1016/S2213-8587(16)30100-0)

26 Williams TA, Lenders JWM, Mulatero P, Burrello J, Rottenkolber M, Adolf C, Satoh F, Amar L, Quinkler M, Deinum J et al. Outcomes after adrenalectomy for unilateral primary aldosteronism: an international consensus on outcome measures and analysis of remission rates in an international cohort. Lancet Diabetes and Endocrinology 20175 689-699. (https://doi.org/10.1016/S2213-8587(17)30135-3)

27 Hoeymans N, van Lindert H \& Westert GP. The health status of the Dutch population as assessed by the EQ-6D. Quality of Life Research 200514 655-663. (https://doi.org/10.1007/s11136-004-1214-z)

28 Kempers MJE, Lenders JWM, van Outheusden L, van der Wilt GJ, Schultze Kool LJ, Hermus ARMM \& Deinum J. Systematic review: diagnostic procedures to differentiate unilateral from bilateral adrenal abnormality in primary aldosteronism. Annals of Internal Medicine 2009151 329-337. (https://doi.org/10.7326/0003-4819151-5-200909010-00007)

29 Doppman JL \& Gill JR. Hyperaldosteronism: sampling the adrenal veins. Radiology 1996198 309-312. (https://doi.org/10.1148/ radiology.198.2.8596821)

30 Seccia TM, Miotto D, De R, Pitter G, Mantero F, Pessina AC \& Rossi GP. Adrenocorticotropic hormone stimulation during adrenal vein sampling for identifying surgically curable subtypes of primary aldosteronism: comparison of 3 different protocols. Hypertension 200953 761-766. (https://doi.org/10.1161/ HYPERTENSIONAHA.108.128553)

31 Rossi GP, Ganzaroli C, Miotto D, De Toni R, Palumbo G, Feltrin GP, Mantero F \& Pessina AC. Dynamic testing with high-dose adrenocorticotrophic hormone does not improve lateralization of aldosterone oversecretion in primary aldosteronism patients. Journal of Hypertension 200624 371-379. (https://doi.org/10.1097/01. hih.0000202818.10459.96)

32 Rossitto G, Maiolino G, Lenzini L, Bisogni V, Seccia TM, Cesari M, Iacobone M \& Rossi GP. Subtyping of primary aldosteronism with adrenal vein sampling: hormone- and side-specific effects of cosyntropin and metoclopramide. Surgery 2018163 789-795 . (https://doi.org/10.1016/j.surg.2017.09.032)

33 Miotto D, De R, Pitter G, Seccia TM, Motta R, Vincenzi M, Feltrin G \& Rossi GP. Impact of accessory hepatic veins on adrenal vein sampling for identification of surgically curable primary aldosteronism. Hypertension 200954 885-889. (https://doi. org/10.1161/HYPERTENSIONAHA.109.134759)

34 Omura K, Ota H, Takahashi Y, Matsuura T, Seiji K, Arai Y, Morimoto R, Satoh F \& Takase K. Anatomical variations of the right adrenal VeinNovelty and significance. Hypertension 201769 428-434. (https://doi.org/10.1161/HYPERTENSIONAHA.116.08375)

35 Espiner EA, Ross DG, Yandle TG, Richards AM \& Hunt PJ. Predicting surgically remedial primary aldosteronism: role of adrenal scanning, posture testing, and adrenal vein sampling. Journal of Clinical Endocrinology and Metabolism 200388 3637-3644. (https://doi. org/10.1210/jc.2002-022051)

36 Rossitto G, Miotto D, Battistel M, Barbiero G, Maiolino G, Bisogni V, Sanga V \& Rossi GP. Metoclopramide unmasks potentially misleading contralateral suppression in patients undergoing adrenal vein sampling for primary aldosteronism. Journal of Hypertension 201634 2258-2265. (https://doi.org/10.1097/HJH.0000000000001082)

37 Rossi GP. Prevalence and diagnosis of primary aldosteronism. Current Hypertension Reports 201012 342-348. (https://doi.org/10.1007/ s11906-010-0134-2)

38 Rossitto G, Battistel M, Barbiero G, Bisogni V, Maiolino G, Diego M, Seccia TM \& Rossi GP. The subtyping of primary aldosteronism by adrenal vein sampling: sequential blood sampling causes factitious lateralization. Journal of Hypertension 201836 335-343. (https://doi. org/10.1097/HJH.0000000000001564)

39 Yoneda T, Karashima S, Kometani M, Usukura M, Demura M, Sanada J, Minami T, Koda W, Gabata T, Matsui O et al. Impact of new quick gold nanoparticle-based cortisol assay during adrenal vein sampling for primary aldosteronism. Journal of Clinical Endocrinology and Metabolism 2016101 2554-2561. (https://doi.org/10.1210/ jc.2016-1011)

40 Cesari M, Ceolotto G, Rossitto G, Maiolino G, Seccia TM \& Rossi GP. The intra-procedural cortisol assay during adrenal vein sampling: rationale and design of a randomized study (I-Padua). High Blood Pressure and Cardiovascular Prevention 201724 167-170. (https://doi. org/10.1007/s40292-017-0192-5)

41 Ceolotto G, Antonelli G, Maiolino G, Cesari M, Rossitto G, Bisogni V, Plebani M \& Rossi GP. Androstenedione and 17- $\alpha$-hydroxyprogesterone are better indicators of adrenal vein sampling selectivity than cortisol novelty and significance. Hypertension 201770 342-346. (https://doi.org/10.1161/ HYPERTENSIONAHA.117.09415)

42 Yamazaki Y, Nakamura Y, Omata K, Ise K, Tezuka Y, Ono Y, Morimoto R, Nozawa Y, Gomez-Sanchez CE, Tomlins SA et al. Histopathological classification of cross-sectional image negative hyperaldosteronism. Journal of Clinical Endocrinology and Metabolism 2017102 1182-1192. (https://doi.org/10.1210/jc.2016-2986)

43 Reincke M, Beuschlein F, Latronico AC, Arlt W, Chrousos GP \& Allolio B. Expression of adrenocorticotrophic hormone receptor mRNA in human adrenocortical neoplasms: correlation with P450scc expression. Clinical Endocrinology 199746 619-626. (https://doi. org/10.1046/j.1365-2265.1997.1991009.x)

44 Arnaldi G, Mancini V, Costantini C, Giovagnetti M, Petrelli M, Masini A, Bertagna X \& Mantero F. ACTH receptor mRNA in human adrenocortical tumors: overexpression in aldosteronomas. Endocrine Research 199824 845-849. (https://doi. org/10.3109/07435809809032695) 
45 Schubert B, Fassnacht M, Beuschlein F, Zenkert S, Allolio B \& Reincke M. Angiotensin II type 1 receptor and ACTH receptor expression in human adrenocortical neoplasms. Clinical Endocrinology 200154 627-632. (https://doi.org/10.1046/j.13652265.2001.01253.x)

46 Seccia TM, Fassina A, Nussdorfer GG, Pessina AC \& Rossi GP. Aldosterone-producing adrenocortical carcinoma: an unusual cause of Conn's syndrome with an ominous clinical course. Endocrine-Related Cancer 200512 149-159. (https://doi.org/10.1677/ erc.1.00867)

47 Zwermann O, Suttmann Y, Bidlingmaier M, Beuschlein F \& Reincke M. Screening for membrane hormone receptor expression in primary aldosteronism. European Journal of Endocrinology 2009160 443-451. (https://doi.org/10.1530/EJE-08-0711)
48 Durand J, Lampron A, Mazzuco TL, Chapman A \& Bourdeau I. Characterization of differential gene expression in adrenocortical tumors harboring $\beta$-catenin (CTNNB1) mutations. Journal of Clinical Endocrinology and Metabolism 201196 E1206-E1211. (https://doi. org/10.1210/jc.2010-2143)

49 Murakami M, Yoshimoto T, Nakabayashi K, Tsuchiya K, Minami I, Bouchi R, Izumiyama H, Fujii Y, Abe K, Tayama C et al. Integration of transcriptome and methylome analysis of aldosterone-producing adenomas. European Journal of Endocrinology 2015173 185-195. (https://doi.org/10.1530/EJE-15-0148)

50 Zhou J, Lam B, Neogi SG, Yeo GSH, Azizan EAB \& Brown MJ. Transcriptome pathway analysis of pathological and physiological aldosterone-producing human tissues. Hypertension $2016 \mathbf{6 8}$ 1424-1431. (https://doi.org/10.1161/HYPERTENSIONAHA.116.08033)

Received 18 October 2018

Revised version received 7 May 2019

Accepted 5 June 2019 